\title{
Pentingnya Pembentukan Karakter Peserta Didik for The Best Future di UPTD SMPN 1 Siabu Mandailing Natal
}

\author{
Ardina Khoirun Nisa \\ Jurusan Hukum Perdata, Prodi Hukum Keluarga Islam \\ STAIN Mandailing Natal \\ *e-mail: ardinas88@gmail.com \\ *Phone: 085262144115
}

Informasi Artikel

Diterima Redaksi: 10 Desember 2021

Revisi Akhir: 29 Desember 2021

Diterbitkan Online: 15 Januari 2022

Kata Kunci:

karakter, moral, peserta didik
Abstrak

Peserta didik yang berkarakter akan bertindak sesuai dengan aturan dan kaidah-kaidah yang berlaku di lingkungan sekitarnya. Bangsa Indonesia saat ini sedang mengalami krisis, yaitu krisis kejujuran, tanggung jawab, tidak berpikir jauh ke depan, disiplin, kebersamaan, keadilan, dan kepedulian. tujuan dari Pengabdian Kepada Masyarakat yang dilaksanakan oleh kelompok kami ini adalah untuk meningkatkan potensi peserta didik agar menjadi manusia yang beriman dan bertakwa kepada Tuhan Yang Maha Esa, berakhlak mulia, sehat, cakap, kreatif, mandiri, dan menjadi warga negara yang demokratis serta bertanggung jawab, agar terciptanya pendidikan yang berkarakter. Metode dalam kegiatan ini dilakukan secara bertahap yaitu dengan melihat masalah yang muncul kemudian menyelesaikan gejala yang muncul tersebut

\section{PENDAHULUAN}

Abad 21 kini dunia pendidikan masih menjadi sorotan karena dianggap belum mampu mendidik generasi muda bangsa Indonesia menjadi pribadi yang memiliki akhlak mulia, berkarakter, atau bermoral. Bangsa Indonesia saat ini sedang mengalami krisis, yaitu krisis kejujuran, tanggung jawab, tidak berpikir jauh ke depan, disiplin, kebersamaan, keadilan, dan kepedulian. Masalah kemerosotan moral dalam dunia pendidikan antara lain diindikasikan dengan merebaknya kasus penyalahgunaan narkoba, pergaulan bebas, kriminalitas, perjokian, ijazah palsu, dan berbagai tindak kekerasan lainnya. Selain itu, banyak generasi muda yang gagal menampilkan akhlak terpuji seperti kesopanan, keramahan, tenggang rasa, rendah hati, suka menolong, dan solidaritas sosial. [1]

Akibatnya, perhatian yang diberikan oleh dunia pendidikan nasional terhadap pendidikan moral selama ini masih kurang maksimal mencapai tujuannya. Sehingga bisa disimpulkan metode pendidikan di bidang moral masih memiliki kelemahan, karena difokuskan pada aspek kognitif yang mewajibkan siswa untuk mengetahui dan menghafal konsep tanpa pemahaman akan perasaan, emosi, dan nurani sehingga kurang memperhatikan pengembangan kepribadian. Selain itu, tidak dilakukan praktik perilaku dan penerapan nilai-nilai budi pekerti dalam kehidupan di sekolah, dan juga selama ini pendidikan lebih berpegang pada model belajar untuk mendapatkan angka. Berdasarkan hal tersebut dapat dengan jelas diartikan bahwa pendidikan yang seutuhnya ialah pendidikan yang tidak hanya mencerdaskan pikiran tetapi juga membentuk karakter yang bermoral.[2]

Hakikatnya akan terjadi persaingan pengaruh pada masalah penguatan pendidikan karakter. Diperlukan penguatan karakter pada pembelajaran anak agar tidak terus menerus dihadapkan pada dampak negatif revolusi industri 4.0, disamping itu kita juga dapat memanfaatkan kemajuan teknologi yang dapat menunjang keberhasilan penguatan pendidikan karakter peserta didik. Namun permasalahan yang terjadi sekarang, seiring dengan telah 
lahirnya gadget di kalangan anak-anak, sedikit demi sedikit telah mengikis nilainilai luhur dan karakter bangsa yaitu Pancasila.[3]

Fakta ini yang menyebabkan pembentukan karakter menjadi penting diterapkan sesuai dengan Peraturan Presiden Nomor 87 Tahun 2017. Dalam Pasal 2 disebutkan bahwa terdapat tujuan pendidikan karakter yaitu:

a. membangun dan membekali Peserta Didik sebagai generasi emas Indonesia Tahun 2045 dengan jiwa Pancasila dan pendidikan karakter yang baik guna menghadapi dinamika perubahan di masa depan;

b. mengembangkan platform pendidikan nasional yang meletakkan pendidikan karakter sebagai jiwa utama dalam penyelenggaraan pendidikan bagi Peserta Didik dengan dukungan pelibatan publik yang dilakukan melalui pendidikan jalur formal, nonformal, dan informal dengan memperhatikan keberagaman budaya Indonesia; dan

c. merevitalisasi dan memperkuat potensi dan kompetensi pendidik, tenaga kependidikan, Peserta Didik, masyarakat, dan lingkungan keluarga dalam mengimplementasikan PPK.[4]

Peserta didik yang berkarakter akan bertindak sesuai dengan aturan dan kaidahkaidah yang berlaku di lingkungan sekitarnya. Peserta didik dapat bersikap sopan santun, bertanggungjawab, dan menjunjung tinggi kearifan local daerahnya. Peran sekolah dalam mengimplementasikan karakter ini sangat besar pengaruhnya dikarenakan berupaya untuk melatih intelektual dan karakter peserta didik.[5]

Sehubungan dengan tujuan yang tersebut di atas, maka kelompok pengabdi melakukan pengabdian yang bertempat di UPTD SMPN 1 Siabu. Dimana tujuan dari Pengabdian Kepada Masyarakat yang dilaksanakan oleh kelompok kami ini adalah untuk meningkatkan potensi peserta didik agar menjadi manusia yang beriman dan bertakwa kepada Tuhan Yang Maha Esa, berakhlak mulia, sehat, cakap, kreatif, mandiri, dan menjadi warga negara yang demokratis serta bertanggung jawab, agar terciptanya pendidikan yang berkarakter, tidak hanya berkarakter di sekolah namun juga di lingkungan masyarakat mereka.

\section{METODE}

Pelaksanaan kegiatan pengabdian kepada masyarakat ini berlokasi di SMPN 1 Siabu yang merupakan sekolah lanjutan tingkat pertama dan pertama kali berdiri di kecamatan Siabu, pada tanggal 12 Oktober 1957 dan beralamat di Jalan Imam Bonjol Lingkungan I Kelurahan Siabu Kabupaten Mandailing Natal. SMP Negeri 1 Siabu memiliki 1 Ruang Kantor Tata Usaha dan Ruang Kepala Sekolah, Laboratorium IPA, Perpustakaan, Laboratorium Komputer, Ruang Pertemuan, Ruang OSIS, Ruang UKS, Musholla, Ruang BP, Kantin, WC Siswa, WC Guru, serta Lapangan Olahraga. Jumlah Tenaga Pendidik di sekolah ini sebanyak 46 Orang dan jumlah Tenaga Kependidikan sebanyak 6 orang. Adapun jumlah siswa pada tahun pelajaran 2019/2020 yaitu sebanyak 341 orang, yang terdiri dari 195 orang berjenis kelamin lakilaki dan sisanya 176 orang berjenis kelamin perempuan.

Adapun metode dalam kegiatan ini dilakukan secara bertahap yaitu dengan melihat masalah yang muncul kemudian menyelesaikan gejala yang muncul tersebut. Tahapan dalam kegiatan ini ada tiga tahap yaitu:

1. Tahap Persiapan

Pada tahap ini kelompok pengabdi melakukan survei ke lokasi untuk melihat gejala-gejala apa yang menjadi permasalahan-permasalahan yang dihadapi oleh pendidik dalam pembentukan karaker peserta didik. Kegiatan ini dilakukan dengan koordinasi kepada Kepala Sekolah SMPN 1 Siabu.

2. Tahap Pelaksanaan Kegiatan pengabdian

Pada tahap ini kelompok pengabdi melaksanakan kegiatan pembentukan karakter peserta didik melalui kegiatan seminar pendidikan dengan penyampaian materi yang bertemakan kenakalan remaja dan manfaat dari menabung. Dimana dalam materi disebutkan tentang nilai-nilai yang perlu di adopsi oleh peserta didik untuk menjadi insan yang berkarakter. Tahap ini adalah tahap dimana dilaksanakan 
diskusi tanya jawab terhadap peserta didik terkait pemahaman mereka dengan materi yang disampaikan oleh para narasumber.

3. Tahap Evaluasi

Pada tahap ini dilakukan pelaporan dan penerbitan karya ilmiah ke jurnal yang telah ditargetkan sebelum dilakukannya pengabdian ini.

\section{HASIL DAN PEMBAHASAN}

Pelaksanaan kegiatan pengabdian ini melalui tahap-tahap dan menghasilkan halhal berikut ini:

1. Koordinasi ke pihak sekolah SMPN 1 Siabu

Koordinasi ini dilaksanakan terkait waktu pelaksanaan kegiatan pengabdian dan bagaimana sarana prasarana yang berkaitan dengan peserta didik yang akan mengikuti kegiatan pengabdian, ruangan yang digunakan dan hal lainnya yang mendukung berlangsungnya kegiatan pengabdian. Kegiatan pengabdian dihadiri oleh 60 orang peserta didik dan diadakan di aula SMPN 1 Siabu.

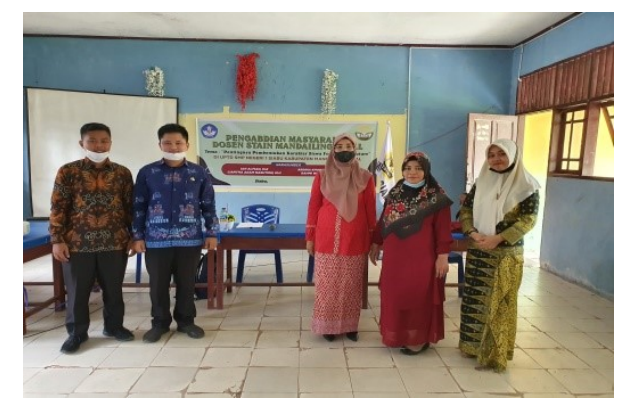

Gambar 1. Poto Bersama dengan Kepala Sekolah SMPN 1 Siabu

2. Pemahaman tentang pembentukan karakter for the best future melalui seminar

Pelaksanaan seminar dengan penyampaian materi yang berhubungan dengan pembentukan karakter, yang dilaksanakan pada Kamis, 04 November 2021. Ada dua materi yang dipaparkan, salah satu materi yang disampaikan pada kegiatan ini adalah kenakalan remaja. Kenakalan remaja adalah suatu tindakan yang melanggar norma, aturan atau hukum dalam masyarakat yang diamananya pelakunya adalah remaja atau transisi masa anak-anak ke dewasa. Kenakalan remaja merupakan gejala sosial yang pada akhirnya menyebabkan perilaku menyimpang, seperti berkelahi, keluyuran, membolos sekolah, pergi dari rumah tanpa pamit, mengendarai kendaraan bermotor tanpa SIM, mengambil barang orang tua atau orang lain tanpa ijin, penyalahgunaan obat terlarang, seks bebas, pencurian. Ini merupakan salah satu bentuk penyimpangan yang harus dihindari oleh peserta didik untuk membentuk karakter yang berakhlak mulia.

Materi lainnya adalah manfaat menabung. Menabung adalah berlatih menahan diri untuk membeli sesuatu dengan dana yang dimiliki. Menabung juga memberikan dampak yang positif. Salah satu manfaat dari menabung yaitu dapat mencegah kebiasaan berhutang, menabung juga memberikan manfaat dapat mengatur keuangan sendiri. Dimana dengan menabung sejak dini dapat meraih apa yang dibutuhkan di masa yang akan datang. Menabung dapat dilakukan di Bank dengan mudah di zaman sekarang. Menabung merupakan kegiatan positif yang dapat mewujudkan visi misi sekolah SMPN 1 Siabu, yaitu " religius, berakhlak mulia, cerdas, terampil dan mandiri".

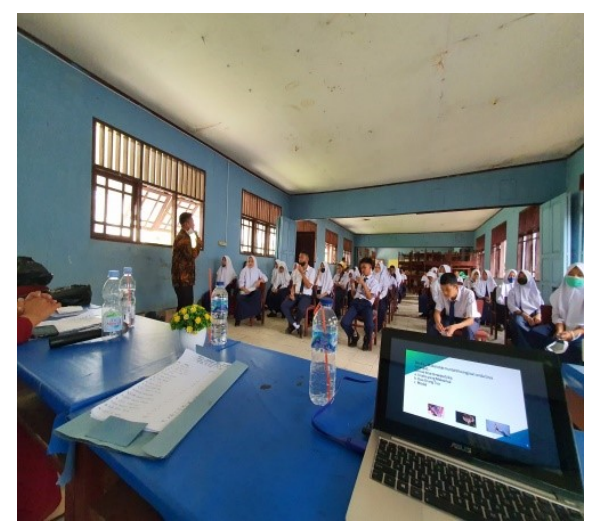

Gambar 2. Penyampaian Materi

3. Diskusi dan Tanya Jawab

Diskusi dan tanya jawab dilakukan untuk melihat seberapa paham peserta didik akan materi yang disampaikan dari kegiatan seminar. Dari kegiatan diskusi ini dapat dinilai apakah peserta didik sudah memiliki karakter seperti yang diharapkan dari tujuan pengabdian ini. Terlihat bahwa para peserta didik sangat antusias dan mengikuti setiap rangkaian acara dalam kegiatan seminar yang dilakukan. Nilai menghormati dan 
menghargai dari peserta didik dapat dinilai pada kegiatan ini.

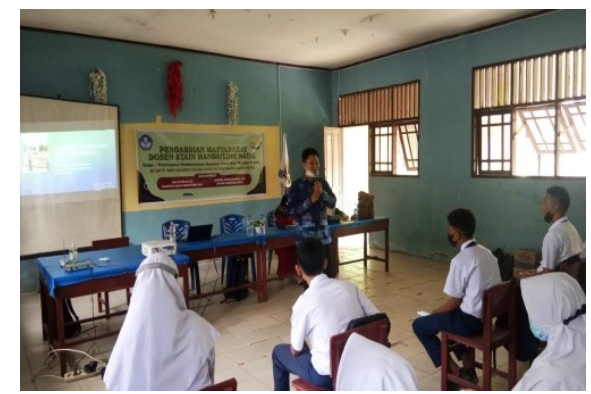

Gambar 3. Diskusi dan Tanya jawab

\section{Games}

Games atau permainan untuk melihat karakter peserta didik dalam pembentukan karakter apakah sudah memiliki kejujuran dalam dirinya masing-masing. Disini pengabdi melakukan permainan dimana setiap siswa yang memiliki warna sepatu yang sama diperintahkan untuk berpindah dari tempat duduknya masing-masing. Hasil dari permainan ini sangat positif dikarenakan siswa yang diperintahkan tersebut melaksanakan sesuai arahan dari para pengabdi. Nilai kejujuran adalah sisi yang diambil dari permainan tersebut.

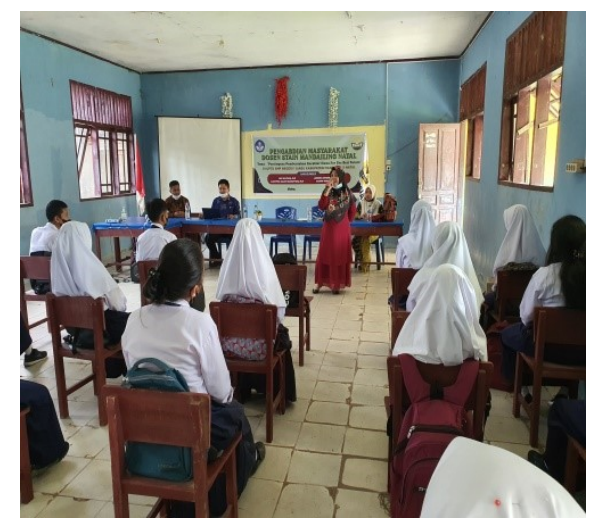

Gambar 4. Games Kejujuran

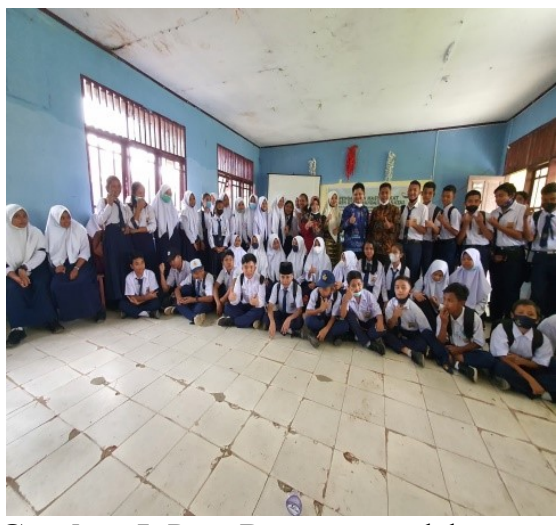

Gambar 5. Poto Bersama setelah games
6. Evaluasi

Dilakukan pelaporan dan penerbitan karya ilmiah ke jurnal yang telah ditargetkan sebelum dilakukannya pengabdian ini.

\section{KESIMPULAN}

Berdasarkan pengabdian yang telah dilakukan maka dapat ditarik kesimpulan yaitu dengan tercapainya tujuan dari pembentukan karakter di SMPN 1 Siabu yaitu dibuktikan dengan antusias dan penerapan dari nilai-nilai moral religius, berakhlak mulia, cerdas, terampil dan mandiri sesuai dengan visi misi SMPN 1 Siabu Mandailing Natal. Penguatan pendidikan karakter merupakan upaya untuk menumbuhkan dan membekali generasi penerus agar memiliki bekal karakter baik, keterampilan literasi yang tinggi, dan memiliki kompetensi unggul di era revolusi industri keempat yaitu mampu berpikir kritis dan analitis, kreatif, komunikatif, dan kolaboratif

\section{SARAN}

Berdasarkan pengabdian yang dilakukan adapun saran dari pengabdi adalah pembentukan karakter merupakan hal yang sangat fundamental dan penerapan dari pendidikan karakter ini harus diselipkan disetiap pembelajaran yang dilakukan di sekolah, misalnya dengan kegiatan seminar pendidikan yang dilakukan.

\section{UCAPAN TERIMA KASIH}

Ucapan terima kasih kepada pihak sekolah SMPN 1 Siabu terutama kepada Kepala Sekolah yang sudah bersedia menerima kelompok kegiatan pengabdian ini. Alhamdulillah kegiatan berjalan lancar dengan dukungan dan bantuan dari berbagai pihak yang tidak disebutkan secara menyeluruh dalam pelaksanaan kegiatan pengabdian ini.

\section{REFERENSI}

[1] A. Sudrajat, "Mengapa Pendidikan Karakter," J. Pendidik. Karakter, vol. I, no. 1, pp. 47-58, 2011, doi: 10.21831/jpk.v1i1.1316.

[2] A. A. Hasibuan, D. Syah, and M. Marzuki, "Manajemen Pendidikan Karakter Di Sma," Tarbawi J. 
Keilmuan Manaj. Pendidik., vol. 4, no. 02, p. 191, 2018, doi: 10.32678/tarbawi.v4i02.1230.

[3] M. P. Dr. Otib Satibi Hidayat, "Pendidikan Karakter Anak Sesuai Pembelajaran Abad ke-21 by Dr. Otib Satibi Hidayat, M.Pd. (zlib.org).pdf." pp. 1-171, 2020.

[4] Presiden Republik Indonesia, "Perpres no. 87 Tahun 2017," 6 Sept. 2017, pp. 1-14, 2017, [Online]. Available:

https://setkab.go.id/inilah-materiperpres-no-87-tahun-2017-tentangpenguatan-pendidikankarakter/\%0Ahttps://peraturan.bpk.g o.id/Home/Details/73167/perpresno-87-tahun-2017.

[5] M. Z. Ahmadi, H. Haris, and M. Akbal, "Implementasi Program Penguatan Pendidikan Karakter Di Sekolah," Phinisi Integr. Rev., vol. 3, no. 2, p. 305, 2020, doi: 10.26858/pir.v3i2.14971. 